15. Meara JG, Shah S, Li KK, Cunningham MJ. The Odontogenic keratocyst: A 20-year clinicopathologic review. Laryngoscope 1998; 108:280-283.

16. Barry CP, Kearns GJ. Case report-odontogenic keratocysts: enucleation, bone grafting and implant placement: an early return to function. J Ir Dent Assoc 2003;49:83-88.

17. Koseoglu BG, Atalay B, Erdem MA. Odontogenic cysts: a clinical study of 90 cases. J Oral Sci 2004;46:253-257.
Address for correspondence:

Eduardo Dias Ribeiro Rua Severino Alves Ayres, 1271 - Tambauzinho, 58042-120 João Pessoa, PB, Brazil

Tel.: $+55-83-3225-1636$ e-mail: eduardodonto@yahoo.com.br (or) lacetbmf@oi.com.br

\title{
LARYNGEAL CYST - CASE REPORT
}

\author{
D.M. Mahore, * A.M.Pawade,* N.M.Pande, ${ }^{* *}$ \\ B.D. Bokare, ${ }^{* * *}$ S.K.T. Jain****
}

Abstract: Laryngeal cysts are rare, generally benign lesions which can affect all age groups. We report a case of huge supraglottic cyst. A 19 years old female presented with hoarseness and airway obstruction secondary to large cystic mass involving the entire right side of supraglottis attached to right anjepiglottic fold. Cyst was dissected by laryngofissure approach. On regular follow up for 3 years there is no recurrence of the lesion.

Keywords: Laryngeal cyst, supraglottis, laryngofissure

\section{INTRODUCTION:}

Cysts of larynx are usually benign. Interference with normal laryngeal function, specifically respiration, has resulted in death in infants and adults. The majorities of cysts seen in adulthood are asymptomatic or occur with mild symptoms such as a lump in throat or voice alterations. Neonates and infants generally present with stridor. These patients require careful evaluation since the smaller airway manifests a much greater potential for obstruction. The most common site of laryngeal cysts is on the lingual surface of epiglottis but the lesions may occur within the endolarynx and can involve aryepiglottic folds. Differentiation from malignant tumour as well as supraglottitis must be made during evaluation. Treatment is dependent on size, anatomical location and degree of respiratory compromise. Tracheostomy may be necessary to ensure and protect a patient airway prior to definitive treatment of the problem. Main stay of treatment is surgical excision by various ways. We report successful management of huge supraglottic cyst by laryngofissure method.

\section{CASE REPORT:}

The present case is a 19 years old girl, who presented with complaints of change of voice since two months and difficulty in respiration since one month. On indirect laryngoscopic examination there was huge globular cyst like lesion involving right side of supraglottis and rest of laryngopharynx was not seen. Neck was normal and rest of ENT examination revealed no
abnormality.Direct laryngoscopy was done which revealed wide based cystic lesion in supraglottis attached to right aryepiglottic fold. CT larynx both plain and contrast (Scan 1) was done which showed well defined hypodense cystic lesion of size approximately $3.2 \times 3.1 \mathrm{~cm}$ in supraglottis with smooth enhancment of cyst wall and effacement of right aryepiglottic fold. Cyst was operated under general anaesthasia by laryngofissure approach (Fig I). Cyst was found to be arising from right aryepigllotic fold, cyst was dissected completely and was sent for histopathological examination. Tracheostomy was done at the end of procedure anticipating postoperative oedema. Size of cyst was $3 \times 3 \mathrm{~cm}$ and on aspiration was found to contain thin mucinous fluid and histopathological report was simple cyst. Post operatively patient was put on antibiotics and steroids in tapering doses for 10 days and was decanulated at the end of three weeks. On regular follow up of patient, there is no evidence of recurrence of cyst.

\section{DISCUSSION:}

Cysts of larynx are rare lesions. They are routinely identified on mirror laryngoscopy and may go untreated if asymptomatic, their incidence is unknown. In 1938, New and Erich reported 35 cases of cysts of larynx in a series of 722 benign laryngeal tumours. The most common locations of laryngeal cysts are the lingual surface of epiglottis, the free margin of false cords, arytenoids and aryepiglottic folds, pyriform fossa and the ventricle.Larnygeal cysts are found at any age, although they occur less frequently 


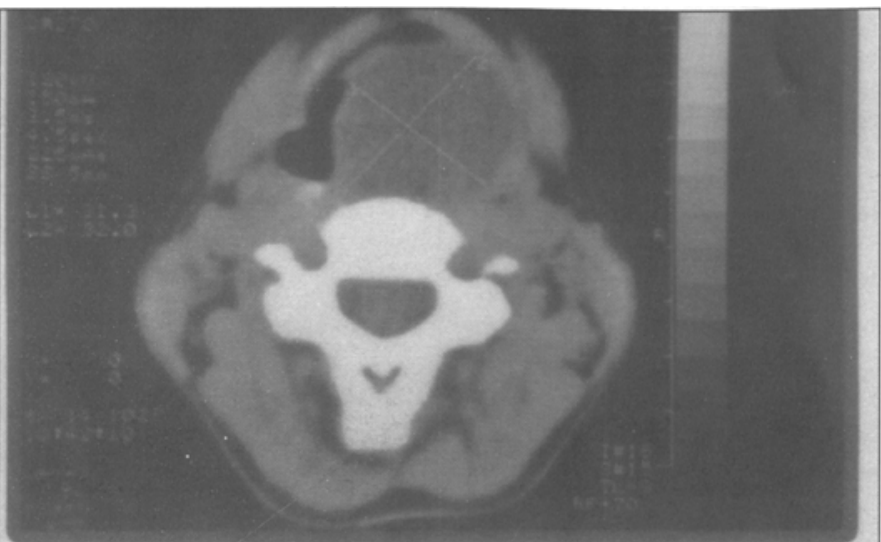

Fig I: CT Scan showing the Laryngeal Cyst

in children than in adults. The sixth decade was the most frequent age range in the series of De Santo et al.Presenting symptom vary with cyst size, age and extension into the airway. Infants, because of their small larynges, may present with dyspnoea and laboured breathing, stridor or difficulty in feeding. The adult complains of symptoms similar to other space occupying lesions of the airway. The origin of these cysts is thought to be from obstruction of the ducts of muous glands resulting in subsequent glandular dilatation.

De Santo et al divided laryngeal cysts into two major divisions saccular and ductal. A third type the thyroid cartilage foraminal cyst was described as an isolated case. Controlling the airway is a formidable task if these patients present with severe airway compromise. An emergent or elective tracheostomy is necessary, if standard endotracheal intubation can not be performed. Puncturing the cyst to allow decompression adds the risk of pulmonary aspiration; this procedure is not recommended prior to securing an airway. Many of these cysts may be treated by utilizing direct laryngoscopy, incision with microsurgical instruments or removal with nasal snare. Giant obstructing cysts may be removed by the transoral route but may require a lateral pharyngotomy or larnygofissure, for complete excision. This case report typifies supraglotlic cyst.

In summary, for the giant cysts, laryngofissure is the better option for complete clearance.

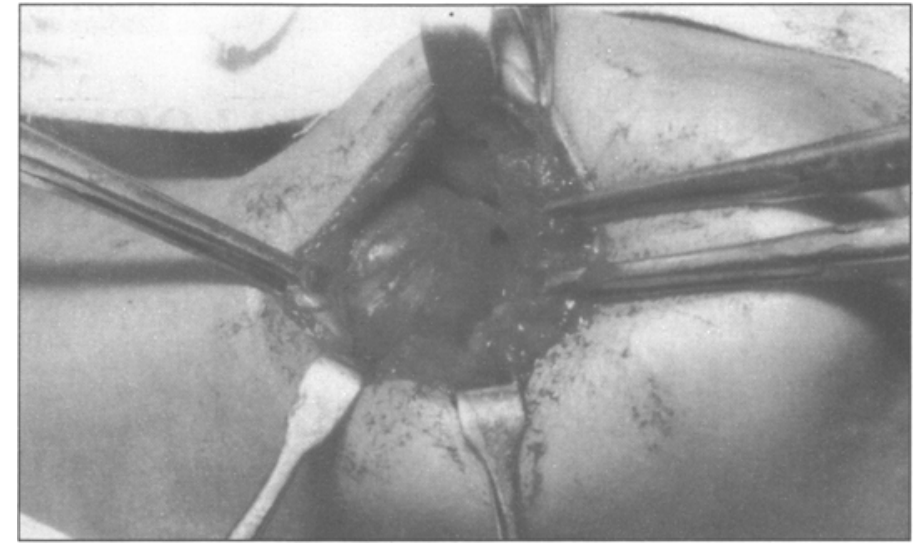

Fig II: Inta-operative photograph showing Laryngeal Cyst after expos

\section{REFERENCES:}

1. Abrampson AL, Zielinsci B; congential laryngeal saccular cysts of the new born. Laryngoscope 94:1580-2, 1984.

2. Booth JB, Birck HG: operative treatment and post operative management of saccular cyst and laryngocele; Arch Otolaryngol $107 ; 500-2 ; 1981$.

3. De Santo LW, Derine KD, Weiland LH: cysts of larynx - classification; laryngoscope 80: 145-76, 1970.

4. Henderson LT, Dennemy JC, Teichgraeber J: Airway -obstructing epiglottic cyst: Ann Otol Rhinol laryngol 94: 473-6; 1985.

5. Lawerence PA, Burgen PA, Wim DWS: laryngeal cyst of the thyroid cartilage Arch otolaryngol 11: 826, 1985.

6. Myerson MC: cysts of larynx: Arch otolaryngol 18: 281-90, 1983

7. Schall LA; An extralaryngeal approach for certain benign lesions of larynx Ann otol Rhinol Layngol 68: 346-55 1959.

8. Van De Water FW: Laryngeal cysts - their surgical management . laryngoscope 83: 1185-94, 1973.

9. Wansa SA, Jones NS, Watkinson J: unusual laryngeal cyst. JLO 104 145-6, 1990

Address for correspondence: Dr.D.M. Mahore, Plot no-P9/A,

Laxminagar, Nagpur-22 